Original Paper http://ajol.info/index.php/ijbcs http://indexmedicus.afro.who.int

\title{
Prospective of infant morbidity and mortality in mothers of patients from 6 to 59 months admitted in two reference hospitals in Niamey, Niger
}

\author{
Sadou KANGAYE ${ }^{1 *}$, Alido SOUMANA ${ }^{4}$, Kamayé MOUMOUNI ${ }^{2}$, \\ Hassane Ali MAZOU ${ }^{5}$, Hassane MOUMOUNI ${ }^{3}$ and Hassimi SADOU ${ }^{1}$ \\ ${ }^{1}$ Laboratory of Nutrition and valorization of Agro-resources. Faculty of Science and Techniques. of Abdou \\ Moumouni University of Niamey. Niger. \\ ${ }^{2}$ Pediatric Emergency Department. Niamey National Hospital. \\ ${ }^{3}$ Faculty of Health Sciences. Abdou Moumouni University. P.O: 131/125 Niamey, Niger. Niamey. \\ ${ }^{4}$ Internal Nutritional Rehabilitation Centre. Pediatric service. National Hospital of Lamordé. P.O: 11653 \\ Niamey, Niger. \\ ${ }^{5}$ Administration of National the Hospital of Niamey. Niger. \\ *Corresponding author; E-mail: kangayesadou@yahoo.com; Tel: (+ 227) 97250084
}

\begin{abstract}
Mothers arrive in pediatric institutions with a medical background psycho-emotionally burdened which affects the quality of the treatments. The aim of this study was to characterize the medical experience of mothers of patients from 6 to 59 months old admitted at the hospital in terms of morbidity and infant mortality. It's a descriptive cross-sectional survey conducted from 16 January to 2 May 2016 in two reference hospitals in Niamey. The mothers were interviewed on the medical history of their children. The study concerned 287 mothers of hospitalized children from 6 to 59 months old. $74 \%$ of them were between 18 and 35 years old; $62.02 \%$ not in school and $87.45 \%$ without income-generating activities. Among the children from 6 to 59 months old hospitalized or dead in the past, boys were leading in number with respectively, $64.52 \%$ and $53.92 \%$. The findings from this study revealed that the hospitalizations and infant death most concerned the children from 6 to 11 months old with respectively, $42 \%$ and $48 \%$. The results also showed that $15.38 \%$ of mothers were unsatisfied of the treatment during their last stay at the hospital. The morbidity was correlated with the sex $(P=0.035)$ and with the age group $(p=0.004)$ whereas the mortality was correlated with the age group only $(\mathrm{P}=0.0001)$. Thus mothers still feel the past medical situation of their children that must be taken into account in the relations among the cures.
\end{abstract}

(C) 2019 International Formulae Group. All rights reserved.

Keywords: Morbidity, mortality, emergency, pediatrics, Niger.

\section{INTRODUCTION}

In the African region countries of the World Health Organization (WHO), infant morbidity and mortality still remain major public health problems. The infant mortality rate was estimated at $119 \%$ compared to 57
$\%$ at the global level and 6\%o in industrialized countries (WHO, 2012). In these countries, more than $70 \%$ of the death of children under five years are due to five major diseases: pneumonia, diarrhea, malaria, measles (Krug et al., 2004 ; WHO, 2004 - 2005) .It's reported 
that the prevalence of anaemia is high in children from 6 to 24 months old and it varies according to the sex and age group (Abdou et al, 2015). It is also established that malnutrition, by weakening the child's immune functions, contributes in large part to this mortality (Stéphane, 2004). In addition to this, there is a delay in the use of care by the persons in charge of the child (Sadou et al., 2016). As a result, patients often arrived at the hospital in an emergency case, sometimes made of hyperthermia (convulsive), anemia or respiratory distress (Sanou, 2012). Therefore, these symptoms represent both the main reasons for consultation and the causes of early childhood death (occurring within 72 hours) in the sub regions (Sanou, 2012; Bazié, 2009). Thus, the daily lives of mothers in our countries are made up of illnesses, hospitalizations and infant death. In order to better understand the state of mind of the consultating mother, it is essential to learn about the morbidity and infant mortality recorded by them. The objective of this study was to characterize the medical experiences with mothers of patients from 6 to 59 months old admitted in the hospital.

\section{MATERIELS AND METHODS Patients}

The study took place from 16 January to 2 May 2016 in two reference hospitals in Niamey (National Hospitals of Niamey (HNN) and National Hospital of Lamordé). It concerned mothers of children from 6 to 59 months old hospitalized in pediatrics' emergency services.

\section{Materials}

- Children's health booklets;

- A semi-structured interview questionnaire;

- Calendar of local events.

\section{Operating Protocol}

The mothers were received on their arrival in the nurses ' room for admission procedures. After stabilization and control of any medical complication in the child, the mother is interviewed on the past event of hospitalizations and death of their children. In order to minimize the effects of methodological limitations (absence of civil status documents or health booklets) and the risks of sub-records of information, the study was more focused on the history of events of major morbidities (hospitalizations) and infant death (including neonatal mortality).

\section{Inclusion criteria}

Any consenting mother with a child from 6 to 59 months old hospitalized during the period of the study in the pediatric emergencies.

\section{Exclusion criteria}

Mothers with obese children, or with edema and those with children less than 6 months old or weighing less than $4000 \mathrm{~g}$ body weight were excluded from the study.

\section{Non - inclusion criteria}

Any mother of hospitalized children from 6 to 59 months old who was not consenting or whose child was clinically unstabilized.

\section{Ethical consideration}

The study was approved by the National Ethics Committee (n'010/2015/CCNE/ July-29-2015) and the Academic Scientific Council of the Abdou Moumouni University, and authorized by the officials of the two hospital centers. The protocol was consistent with the Helsinki declaration of 1975 revised in 2008: Participation in the study was voluntary. The purpose of the study was explained to the mothers and their informed consent was obtained.

\section{Statistical analyses}

The data were entered on the EPI-data 3.1 software and analyzed with the Stata 12 software. The Ch2 test at the $0.5 \%$ threshold of significance was used to search for correlations between the studied parameters.

\section{RESULTS}

Table 1 collects the socio demographic characteristics of mothers. The majority of the 
mothers were from the urban community of Niamey (CUN), (68.64\%) followed by those from the region of Tillabéry (29.27\%) - this region enclave the CUN. Among them, 74\% was between 18 and 35 years old; $62.02 \%$ have not been to school and $87.45 \%$ without income-generating activities.

Table 2 gives the distribution of socio demographic characteristics of children in the past who were hospitalized and/or dead according to the sex and age. In total, $32.40 \%$ of mothers had a hospitalized child and $35.54 \%$ had a dead one. The gender study of the concerned children showed that there were more boys hospitalized (64.52\%) and dead $(53.92 \%)$. The age distribution of hospitalizations and death places the age group $6-11$ months the first with respectively, $42 \%$ and $48 \%$ followed by $12-24$ months with $41 \%$ hospitalizations and $37 \%$ of death. Hospitalizations were statistically correlated with sex $(P=0.035)$ and age $(P=0.004)$. As for mortality, it was only with age $(\mathrm{P}=$ 0.0001).

Table 3 shows the distribution of the causes of death by sex and the age group of children. The main causes of death among boys were fever with $44 \%$ and diarrhea with $35 \%$. In girls, the same causes were also found with relatively less fever, (38\%) than diarrhea, $(45 \%)$. The main causes of death in children from 6 to 11 months old were diarrhea with $44 \%$ and fever with $38 \%$. In children of the age group of $12-24$ months the same causes were found with always a predominance of diarrhea with $50 \%$ versus $30 \%$ of fever.

Table 4 reports the use of pediatric care institutions, the non-satisfaction of mothers and the average duration of previous hospital stays of mothers. Mothers had more frequented hospital structures for boys - 60 hospitalizations on 55 deaths: $110 \%$ vs. $70.22 \%$ among girls. However, mortality at the hospital was more important with girls, with $15.15 \%$ vs. $13.33 \%$ for boys. The mothers had stayed longer in hospital with the boys with 9 days \pm 2 vs. 7 days \pm 2 in girls. $15.38 \%$ of mothers were less satisfied with the care given to children in the age group of 6 11 months. For this same age group, the mothers remained not only for the longest interned ( $8 \pm 2$ days) and had recorded more hospital mortality with $19 \%$.

Table 1: Socio demographic characteristics and medical history of maternal.

\begin{tabular}{lcc}
\hline Characteristics & Geographical origin \\
\hline CUN & Age groups & $197(68,6)$ \\
Tillabéry & $84(29,27)$ \\
Other & $6(2,09 \%)$ \\
& & \\
$<18$ ans & Education level of mother & $11(3,83)$ \\
$18-35$ ans & & $211(73,51)$ \\
$>35$ ans & $65(22,66)$ \\
Not in school & Income generating activity & $178(62,02)$ \\
Primary & & $91(31,71)$ \\
Secondary & & $14(4,88)$ \\
Superior & Medical experience of the children of the Mother & $4(1,39)$ \\
With & & $36(12,54)$ \\
Without & & $251(87,45)$ \\
& & $93(32,40)$ \\
History of hospitalization & $102(35,54)$ \\
History of death & & \\
\hline
\end{tabular}


Table 2: Distribution of morbidity and infant mortality by sex and age groups.

\begin{tabular}{lcccc}
\hline Characteristics & \multicolumn{1}{c}{ Hospitalized } & $\boldsymbol{p}$ & Dead & $\boldsymbol{p}$ \\
\cline { 2 - 5 } & \multicolumn{4}{c}{ Sex (N\%) } \\
Girls & $33(35,48) \mathrm{b}$ & 0,035 & $47(46,07) \mathrm{b}$ & 0,650 \\
Boys & $60(64,52) \mathrm{a}$ & & $55(53,92) \mathrm{a}$ & \\
& & Age group (month) & \\
$6-11$ & $39(41,94) \mathrm{a}$ & 0,004 & $48(47,06) \mathrm{a}$ & 0,0001 \\
$12-24$ & $38(40,86) \mathrm{b}$ & & $38(37,25) \mathrm{b}$ & \\
$25-59$ & $16(17,20) \mathrm{c}$ & & $16(15,69) \mathrm{c}$ & \\
\hline
\end{tabular}

Table 3: Distribution of causes of infant death by sex and age group

\begin{tabular}{llcccc}
\hline Characteristics & \multicolumn{1}{c}{ Fever } & Diarrhea & IRA & Other \\
\cline { 3 - 6 } & & \multicolumn{5}{c}{ (N\%) } \\
\cline { 3 - 6 } Girls & $\mathrm{n}=47$ & $18(38,30) \mathrm{c}$ & $21(44,69) \mathrm{b}$ & $2(4,25) \mathrm{d}$ & $6(12,76) \mathrm{d}$ \\
Boys & $\mathrm{n}=55$ & $24(43,64) \mathrm{b}$ & $19(34,54) \mathrm{d}$ & $4(7,27) \mathrm{a}$ & $8(14,55) \mathrm{b}$ \\
$6-11$ & $\mathrm{n}=48$ & $18(37,5) \mathrm{d}$ & $21(43,75) \mathrm{c}$ & $3(6,25) \mathrm{b}$ & $6(12,5) \mathrm{e}$ \\
$12-24$ & $\mathrm{n}=38$ & $12(31,58) \mathrm{e}$ & $19(50) \mathrm{a}$ & $2(5,26) \mathrm{c}$ & $5(13,16) \mathrm{c}$ \\
& & $11(68,75) \mathrm{a}$ & $0(0,00) \mathrm{e}$ & $1(6,25) \mathrm{b}$ & $4(25) \quad \mathrm{a}$ \\
\hline
\end{tabular}

$\mathrm{Nb}$ : The majority of mothers reported a pronounced state of wasting in dead children

Table 4: Rates of use of care institutions, hospital mortality, non-maternal satisfaction and length of hospital stay

\begin{tabular}{|c|c|c|c|c|}
\hline Characteristics & $\begin{array}{l}\text { * Use of care } \\
\text { institutions (UCI) }\end{array}$ & $\begin{array}{l}\text { Hospital } \\
\text { mortality * }\end{array}$ & $\begin{array}{l}* * \text { Non-satisfaction } \\
(\mathrm{NS}) * * *)\end{array}$ & $\begin{array}{c}* * * \text { Duration } \\
\text { Average Stay } \\
\text { (days) }\end{array}$ \\
\hline & \multicolumn{4}{|c|}{$\mathrm{N}(\%)$} \\
\hline Girl & $33(70,22) b$ & $\begin{array}{c}5 \\
(15,15) \mathrm{a}\end{array}$ & $3(9,09) \quad b$ & $7 \pm 1 b$ \\
\hline Boy & $60(109,9)$ a & $\begin{array}{c}8 \\
(13,33) b\end{array}$ & $7(11,66) \mathrm{a}$ & $9 \pm 2 \mathrm{a}$ \\
\hline $6-11$ & $39(81,25) \mathrm{c}$ & $\begin{array}{c}7 \\
(18,94) \mathrm{a}\end{array}$ & $6(15,38) a$ & $8 \pm 2$ a \\
\hline $12-24$ & $38(106) \quad$ a & $\begin{array}{c}4 \\
(10,52) c\end{array}$ & $4(10,53) b$ & $7 \pm 1 b$ \\
\hline $25-59$ & $16(100) \quad b$ & $2(12,5) b$ & $0(0,00) \mathrm{c}$ & $7 \pm 2 b$ \\
\hline
\end{tabular}




\section{DISCUSSION}

In this study, $32.40 \%$ of mothers stayed at least once in a hospital structure for their children. Boys, are more concerned with hospitalizations $64.52 \% \quad \mathrm{P}=0.035$, and $53.92 \%$ of mothers spent more time in hospital for the latter, $p=0.004$. Indeed, there is sexual discrimination between girls and boys linked to biological or sociocultural factors (Grira, 2007). The age group of $6-11$ month with $42 \%$ is more concerned with hospitalizations and also by deaths with $48 \%$ $(\mathrm{P}=0.0001)$. Our results are higher than those found in Congo Brazzaville (28\%) despite an even greater age range of 1 - 11 months (Mabiala-babela et al., 2009). On the other hand, while in France, infant mortality represents in childhood $\left(\begin{array}{ll}0 & -14\end{array}\right)$ years only $1.04 \%$ of all deaths (Plantaz, 2004) and Madagascar, $7.35 \%$ in children from 1 to 5 years old, (Ranaivoarisoa et al., 2011), the History of death Infants reveals an overall mortality of $35.54 \%$ among mothers. This clearly shows that the home environment influences the child's health (Akoto and Hill, 1988). Infant morbidity and mortality are higher in rural than urban areas. This, because not only is the city a factor in the modernization of behaviour (Caselli et al., 2002), but also because it is characterized by a more concentrated presence of sociocollective infrastructures that contribute to improvement of health indicators (Morrisson and Linskens, 2000). However, our results contrast with these assertions given $68.64 \%$ of the mothers reside in the urban community of Niamey (CUN). This could be related to the fact that the study took place in two urban hospital structures, the young age of mothers with $74 \%$ aged 18 and 35, their non-enrolment with $62.02 \%$ or the absence of incomegenerating activities at, $87.45 \%$ of them. The main causes of death reported by mothers are respectively diarrhea in girls with $44.69 \%$ and in boys, fever with $43.64 \%$. The causes of death found in our series are stackable to those noted in several countries on the African continent. In Congo Brazzaville, between 1 and 4 years, mortality is dominated by severe sepsis $(22.4 \%)$ and malaria (22\%) (Mabiala babela et al., 2009). In Mali, in the pediatric service of CHU Gabriel Touré , malaria (23.9\%), diarrhea, $(20.4 \%)$ and malnutrition $(31.7 \%)$ are the main causes of death (Sidibé et al., 2003). In the Bamako district, the causes of neonatal and infant child death are Acute Respiratory Infections - IRA- , (23.3\%), malaria and diarrhea, (13.3\%), malnutrition (10\%) (Diakité , 2006). At the CHU-pediatric Charles de Gaulle, the IRA (30.6\%), severe malaria $(25.3 \%)$ and infectious gastroenteritis $(22.3 \%)$ were the most lethal (Sib, 2006). In Senegal, mortality is dominated by neonatal (22\%), infectious, (20), respiratory $(16 \%)$, and neurological (12\%) disorders (Sylla et al., 2009). Pediatric Emergency services manage situations for which the presence and medical care are necessary in a short time (Xavier, 1981). In the present study in the length of stay is long and particularly in the mothers of boys, $9 \pm 2$ vs. $7 \pm 1$ in girls. The study of Hospitalizations shows that children from 6 to11 months old are those for whom the mothers remained the longest interned, $(8 \pm 2$ days) and those for whom they are also less satisfied with the benefits with $15.38 \%$. The reasons for their lack of satisfaction are mainly related to the lack of hospitality, the physical conditions of hospitalization and the cost of care and hospital stay. Moreover, while it is recognized that the capacity to take charge of emergencies contributes greatly to the reputation of a health facility (Xavier, 1981), in this study, hospital mortality remains among the highest. It is $15.15 \%$ for girls vs. $14 \%$ for boys and $19 \%$ for children from 6 to 11 months old. However, our results are less than $30 \%$ found in Senegal (Sylla et al., 2009), but they are approaching those reported in Burkina Faso, which are 18.09\%, (Dabiré, 2004), while, hospital mortality is only $2.4 \%$ in Tunisia (Ghorbal, 2009). Also, the care of pediatric emergencies remains a health priority in our countries and on its quality will depend the future of the patient (Xavier, 1981) and that of the community. 


\section{Conclusion}

The situation as described in this study challenges and shows the gap between countries with high health systems and those that are still developing in terms of morbidity and mortality. In addition, for more success, our pediatric benefits need to integrate more, the psycho-emotional dimensions that circumscribe any morbid episode of the Child. Indeed, mothers experience a medical history often marked by high morbidity and infant mortality, punctuated by hospital memories with negative emotional burden. It is therefore important to take this into account in the health-care relationship and to adopt appropriate measures to make pediatric emergency services more attractive, welcoming and competent. Then, the government and its partners must continue the efforts to reduce the three main failures in the management of the child: the delay in the use of care, the difficulties of transport and access to appropriate treatment.

\section{COMPETING INTERESTS}

The authors do not declare any competing interests.

\section{AUTHORS CONTRIBUTIONS}

SK participated in carrying out the work of this research and is the holder of the article, KM, AS field technical supervision, and HS was the director of the research. All declare having read and approved the final version of the manuscript.

\section{ACKNOWLEDGEMENTS}

The authors thank, the Institutional Support Project of Belgian Technical Cooperation in Niger (CTB), the Office of the United Nations Children's Fund in Niamey (Unicef), the personnel of the National Hospitals of Niamey and Lamordé for their disinterested support for the realization of the study.

\section{REFERENCES}

Abdou G Y, Justin B, Mélanie A, Sénami AD, Raymond B, Alphonse S. 2015. Prévalence de l'anémie chez les enfants malnutris de 6 à 59 mois hospitalisés au CHD/Zou-Collines dans le plateau d'Abomey (Centre du Bénin). Int. J. Biol. Chem. Sci., 9(1): 82-90. http://dx.doi.org/10.4314/ijbcs.v9i1.8

Akoto EM, Hill AG. 1988. Morbidité, Malnutrition et Mortalité des Enfants, in Population et Société au sud du Sahara, Tabutin D (ed). L'Harmattan: Paris ; 309-334.

Bazié H. 2009. Profil épidémiologique, clinique et évolutif des patients admis en hospitalisation dans le service de pédiatrie du centre hospitalier universitaire de Yaldago Ouédraogo. Thèse de médecine Ouagadougou, No $42 ; 80 \mathrm{p}$.

Caselli G, Vallin J. 2002. Déterminants de la Mortalité (Tome III). INED : Paris ; 478 p.

Dabiré YG. 2004. Profil des décès précoces dans l'unité des urgences pédiatriques du CHU- YO. Thèse de médecine, Ouagadougou, No $161 ; 89$ p.

Diakité A. 2006. Les facteurs de mortalité néonatale, infantile et juvénile dans le district de Bamako. Thèse de médecine, Bamako.

Ghorbal SF. 2009. Evolution de la morbidité et de la mortalité dans un service de pédiatrie générale: étude comparative entre l'année 1991 et l'année 2007. Thèse de médecine, Tunis.

Grira H. 2007. Les déterminants du statut nutritionnel au Matlab: une analyse empirique ; CNRS ; maison des sciences économiques.

Krug A, Pattinson RC. 2004. Why children die: an under-5 health care survey in Mafekeng region. Afr Med. DOI : 10.7196/SAMJ.2534.94 (3): 202- 06

OMS. 2004. Rapport sur la santé du monde : changer le cours de l'histoire. Genève, $187 \mathrm{p}$.

OMS. 2005. Rapport sur la santé du monde : donnons sa chance à chaque mère et à chaque enfant. OMS : Genève ; $261 \mathrm{p}$.

OMS. 2012. Situation et tendances en 2012 [en ligne] www.who.int. 
Mabiala-Babela. J, Makoumbou PB. 2009. Evolution de la mortalité hospitalière chez l'enfant à Brazzaville (Congo). Med Afr Noire, 56(1) : 5-8.

Morrisson C, Linskens C. 2000. Les facteurs explicatifs de la malnutrition en Afrique subsaharienne ; OECD No 167.

Plantaz D. 2004. Mortalité et morbidité infantiles, CHU Grenoble, Septembre ; 7 $\mathrm{p}$

Ranaivoarisoa R, Rakotoarisoa H. 2011. Morbidité et mortalité des enfants au service de pédiatrie à Antananarivo. Med Afr Noire A., 54(1) : 5-8.11.

Sadou K. 2018 Réhabilitation nutritionnelle à base des laits F75 et F100 de patients âgés de 6 à 59 mois en phase de stabilisation en milieu hospitalier à Niamey (Niger). Int. J. Biol. Chem. Sci., 12(5) : 2016-2029 DOI: https://dx.doi.org/10.4314/ijbcs.v12i5.5

Sanou R. 2012. Caractéristiques des enfants hospitalisés aux urgences pédiatriques $\mathrm{du}$ centre hospitalier universitaire Yaldago Ouédraogo du $1^{\mathrm{er}}$ janvier au 31 décembre 2010. Thèse de médecine Ouagadougou, No $119 ; 114 \mathrm{p}$.

Sib SR. 2006. Analyse de la mortalité des enfants de $0-14$ ans au service de pédiatrie médicale du centre hospitalier universitaire pédiatrique Charles de Gaule de Ouagadougou. Thèse de médecine, No $15,76 \mathrm{p}$

Sidibé T. 2003. Morbidité et mortalité dans le service de pédiatrie du CHU Gabriel Touré au mali. Thèse de médecine, Bamako.

Stéphane A. 2004. Etat nutritionnel et qualité de l'alimentation des enfants de moins de deux ans dans la ville de Damée (Côte-d'Ivoire). Thèse d'étude supérieure spécialisée. Université de Montpelier. 95p.

Sylla A, Gueye M. 2009. Audit des décès aux urgences pédiatriques de Dakar, (Sénégal). Facteurs de risque de décès. Med Afr Noire, 56(10) : 495-500.

Xavier E. 1981. La Morale et la Médecine. Ed. Fernand Nathan ; 23-25. 